논 문 22-11-1

\title{
$\mathrm{SiGe/Si/SiGe} \mathrm{Channel을} \mathrm{이용한} \mathrm{JFET의} \mathrm{전기적} \mathrm{특성}$
}

\section{Electrical Properties of JFET using SiGe/Si/SiGe Channel Structure}

\author{
박병관 ${ }^{1}$, 양현덕 ${ }^{1}$, 최철종 ${ }^{1}$, 김재연 ${ }^{1}$, 심규 환 ${ }^{1, a}$ \\ (B. G. Park', H. D. Yang', C. J. Choi', J. Y. Kim', and K. H. Shim, ${ }^{1, a}$ )
}

\begin{abstract}
The new Junction Field Effect Transistors (JFETs) with Silicon-germanium (SiGe) layers is investigated. This structure uses SiGe layer to prevent out diffusion of boron in the channel region. In this paper, we report electrical properties of SiGe JFET measured under various design parameters influencing the performance of the device. Simulation results show that out diffusion of boron is reduced by the insertion SiGe layers. Because the SiGe layer acts as a barrier to prevent the spread of boron. This proposed JFET, regardless of changes in fabrication processes, accurate and stable cutoff voltage can be controlled. It is easy to maintain certain electrical characteristics to improve the yield of JFET devices.
\end{abstract}

Key Words : JFET, SiGe, Junction, Diffusion, SILVACO

\section{1. 서 론}

일반적으로 $\mathrm{PN}$ 접합에 의해 절연된 게이트를 통해 전류 통로를 제어하는 접합형 전계 효과 트 랜지스터(Junction Field Effect Transistors; JFETs) 는, 입력 임피던스가 크고, 온도에 덜 민감하며, 제 조가 간편하여 $\mathrm{IC}$ 제조에 용이하고, 동작의 해석이 단순하다는 장점을 갖는다. 특히 JFET는 선형적인 전류의 증폭 특성을 갖으며 잡음이 작기 때문에, 감 도가 우수한 음항센서의 증폭회로, 선형성이 우수 한 증폭회로, 입력 계측 증폭 회로 등에 주로 사용 된다. 기존에 사용되는 JFET 소자는 구조와 제조 공정에 따라서, 소자의 전기적 특성, 특히, 컷오프 전압 $\left(\mathrm{V}_{\text {cut-off }}\right)$ 과 드레인-소스 포화 전류( $\left.\mathrm{IDSS}_{\mathrm{DS}}\right)$ 의 변 화가 심하게 발생하여, 소자의 전기적 특성 제어가 어렵고, 소자의 수율이 낮다는 문제점이 있다[1,2].

본 연구에서는 SILVACO 시뮬레이션을 통해 게 이트 전압에 의해 채널이 형성되는 채널 층의 상 하부에 각각 $\mathrm{SiGe}$ 로 이루어진 상부 및 하부 확산

1. 전북대학교 반도체과학기술학과

(전북 전주시 덕진동 1가 664-14)

a. Corresponding Author : khshim@chonbuk.ac.kr

접수일자: 2009.8 .12

1차 심사: 2009.9 .17

심사완표 : 2009. 10. 22
저지충을 삽입한 JFET 소자 구조를 형성하여, 게 이트 접합부의 접합 영역 확산을 저지하고, 상기 게이트 접합부가 계면에서 날카로운 농도 구배를 갖도록 핞으로써, 공정 변화에 마른 전기적 특성의 편차가 작아지는 JFET 소자 구조를 제안하였다. 이는 제조 공정의 변화에 관계없이 컷오프 전압을 정확하고 안정되게 제어할 수 있고 이를 통해 소 자의 수율을 높일 수 있을 것으로 기대된다.

본 논문에서는 제안된 JFET 소자 구조를 설계 한 후, 여러 변수( $\mathrm{Ge}$ 함유량, $\mathrm{SiGe}$ 층 두께, $\mathrm{N}$ 채널 두께)를 변경하면서 JFET의 주요 파라미터의 변 화를 분석하였다.

\section{2. 실 험}

\section{$2.1 \mathrm{Si}$ JFET와 SiGe JFET structure}

그림 1은 제안된 $\mathrm{SiGe} \mathrm{JFET}$ 소자의 단면구조를 나타낸 것이다. SiGe JFET은 게이트 전압에 의해 채널이 형성되는 채널 층의 상하부에 각각 $\mathrm{SiGe}$ 충 을 형성하여 Boron의 확산 현상을 막기 위한 확산 저지층으로 사용하였다. $\mathrm{SiGe} \mathrm{JFET} \mathrm{소자의} \mathrm{공정}$ 순서는 다음과 같다. 반도체 기판 위에 $\mathrm{Si}$ 하부 에 피흥을 성장하고, 접합 영역의 확산을 저지하는 하 


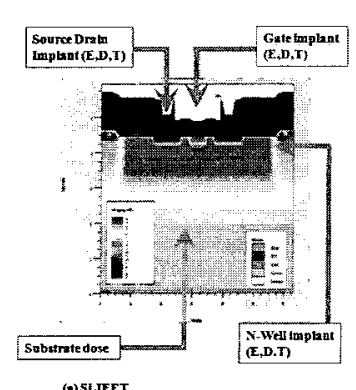

() SIJET

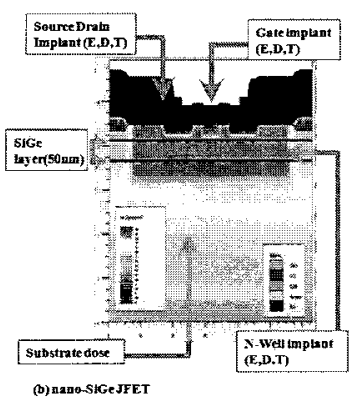

(b) \#ABO-SHGeJFET

그림 1. 제안된 $\mathrm{SiGe-JFET} \mathrm{구조.}$

Fig. 1. Structure of proposed SiGe JFET.

표 1. SiGe JFET 소자의 공정 파라미터.

Table 1. Process parameters of SiGe JFET.

\begin{tabular}{ccc}
\hline Structure & Length $(\mathrm{mm})$ & Condition \\
\hline \hline Gate & 5 & $\begin{array}{c}\mathrm{BF}_{2}, 1.0 \mathrm{E} 15 \mathrm{~cm}^{2}, \\
60 \mathrm{keV}\end{array}$ \\
\hline Source-Drain & 18 & $\begin{array}{c}\text { Phosphorus, } \\
5.0 \mathrm{E} 15 \mathrm{~cm}^{2}, 80 \mathrm{keV}\end{array}$ \\
\hline N-Channel & 0.881 & $\begin{array}{c}\text { Phosphorus, } \\
5.0 \mathrm{E} 15 \mathrm{~cm}^{2}\end{array}$ \\
\hline Substrate(100) & 1.4 & $\begin{array}{c}\text { Boron, } 9.0 \mathrm{E} 18 \mathrm{~cm}^{2}, \\
0.0095 \Omega \cdot \mathrm{cm}\end{array}$ \\
\hline Si top layer & 0.73 & Undoped \\
\hline Si bottom layer & 0.289 & Undoped \\
\hline SiGe layer & 0.05 & Undoped \\
\hline
\end{tabular}

부 확산 저지층을 형성한 후, $\mathrm{Si}$ 채널층을 성장시 키고, 다시 상부 확산 저지층을 성장시킨 후, $\mathrm{Si}$ 상 부 에피층을 성장, 게이트, 소스, 드레인 접합을 형 성한 후, 상,하부 확산 저지층 및 채널층의 측면을 격리하고, 게이트, 소스, 드레인을 형성하였다.

표 2 는 $\mathrm{Si}$ 에서의 $\mathrm{Ea}$ 값과 $\mathrm{SiGe}$ 에서의 $\mathrm{Ea}$ 값을 나타 낸 것이다. $\mathrm{Ge}$ 의 함유량이 $0 \sim 24 \%$ 까지 증가할수록 $\mathrm{Ea}$ 값이 상승 하여 $(2.68 \mathrm{eV} \rightarrow 3.56 \mathrm{eV} \rightarrow 3.68 \mathrm{eV}$ 로 증가한다. 이런 결과 값을 토대로 Boron의 확산속 도를 낮출 수 있어 이를 시뮬레이션에 반영하였다.

$$
D_{B I}^{x}=D I X \cdot 0 \exp \left(-\frac{D I X \cdot E+x \cdot E A F A C T \cdot S I G E}{K T}\right)
$$

DIX.0 = boron activation in sige

DIX.E = boron activation energy in sige

EAFACT.SIGE $=$ SiGe model에 사용되는 보정계수

표 2. Boron \& Phosphorus 확산 활성화 에너지.

Table 2. Boron \& phosphorus of diffusion activation energy.

\begin{tabular}{ccccc}
\hline \hline $\begin{array}{l}\text { Ge } \\
(\%)\end{array}$ & $\begin{array}{c}\text { Strain } \\
\text { state }\end{array}$ & $\begin{array}{c}\text { Temp. } \\
\text { range }\left(^{\circ} \mathrm{C}\right)\end{array}$ & $\begin{array}{c}D_{0} \\
\left(\mathrm{~cm}^{2} / \mathrm{s}\right)\end{array}$ & $\begin{array}{c}Q \\
(\mathrm{eV})\end{array}$ \\
\hline $\begin{array}{c}\text { Diffuser: boron } \\
0\end{array}$ & $\begin{array}{c}\text { relaxed } \\
\text { tensile }\end{array}$ & $800-900$ & $3.4(2.3) \times 10^{-4}$ & $2.68(7)$ \\
0 & $800-900$ & $3.7(8.0) \times 10^{-2}$ & $3.06(21)$ \\
1 & relaxed & $800-925$ & $3.4(2.0) \times 10^{-2}$ & $3.13(6)$ \\
12 & compressive & $800-925$ & $1.5(1.3) \times 10^{0}$ & $3.56(8)$ \\
12 & relaxed & $800-925$ & $2.4(2.4) \times 10^{-1}$ & $3.30(10)$ \\
12 & tensile & $800-925$ & $1.8(1.7) \times 10^{0}$ & $3.48(9)$ \\
24 & compressive & $800-925$ & $3.1(6.9) \times 10^{0}$ & $3.68(22)$ \\
24 & relaxed & $800-925$ & $5.7(7.0) \times 10^{-2}$ & $3.18(13)$ \\
Diffuser: phosphorus & & & \\
0 & relaxed & $825-900$ & $2.0(1.8) \times 10^{-3}$ & $2.80(9)$ \\
7 & relaxed & $825-900$ & $1.8(4.8) \times 10^{-1}$ & $3.24(26)$ \\
12 & relaxed & $800-900$ & $1.1(4.0) \times 10^{-1}$ & $3.11(35)$ \\
24 & relaxed & $800-900$ & $1.7(5.3) \times 10^{3}$ & $4.01(31)$ \\
40 & relaxed & $800-900$ & $1.7(3.8) \times 10^{2}$ & $3.83(22)$ \\
\hline \hline
\end{tabular}

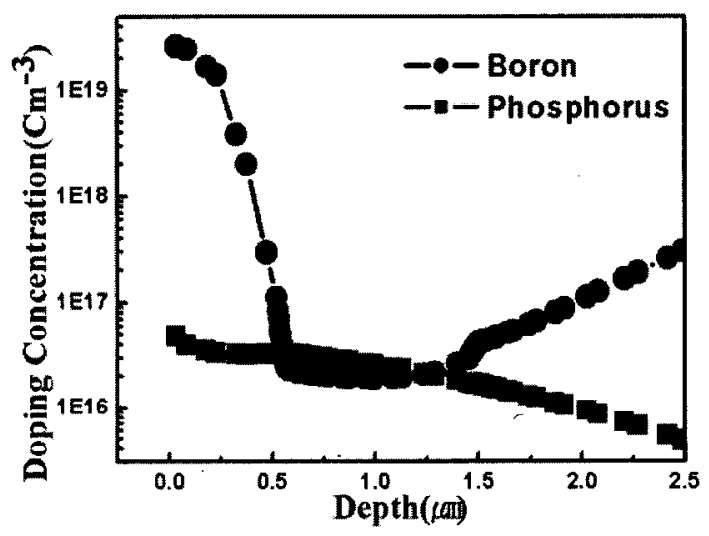

그림 2. SiGe JFET의 깊이 분포.

Fig. 2. Depth profile of SiGe JFET.

식 (1)은 실제 시뮬레이션에 적용되는 $\mathrm{SiGe}$ 에 서의 boron의 확산률 보정계수 관련된 식이다.

\section{2 carrier depth profile}

그림 2 는 $\mathrm{SiGe} J \mathrm{FET}$ 의 게이트 접합 부분에서 $\mathrm{N}$-well 부분까지 수직으로 잘랐을 때 도핑 프로파 일을 나타낸 것이다. $\mathrm{SiGe} \mathrm{JFET의} \mathrm{경우} \mathrm{상하부}$ $\mathrm{SiGe}$ 층으로 인해 Boron의 확산 속도가 감소하는 것을 볼 수 있다.

\section{3. 결과 및 고찰}

3.1 I-V Characteristics of JFET

그림 3(a)는 $\mathrm{V}_{\mathrm{GS}}$ 의 변화에 따른 $\mathrm{Si} J F E T$ 의 $\mathrm{I}-\mathrm{V}$ 


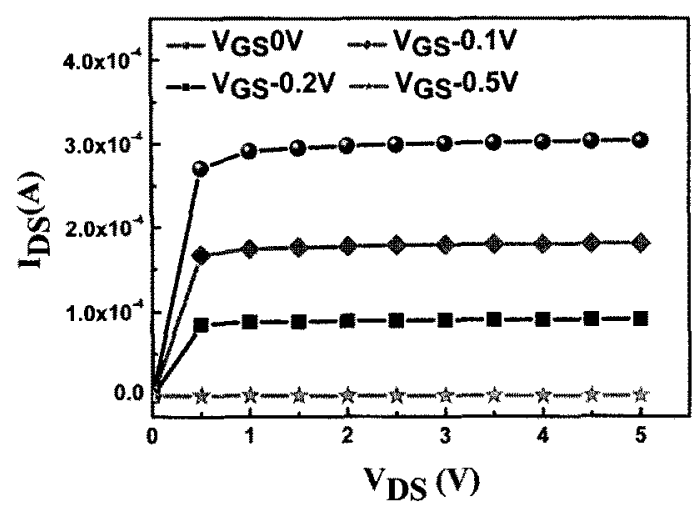

(a)

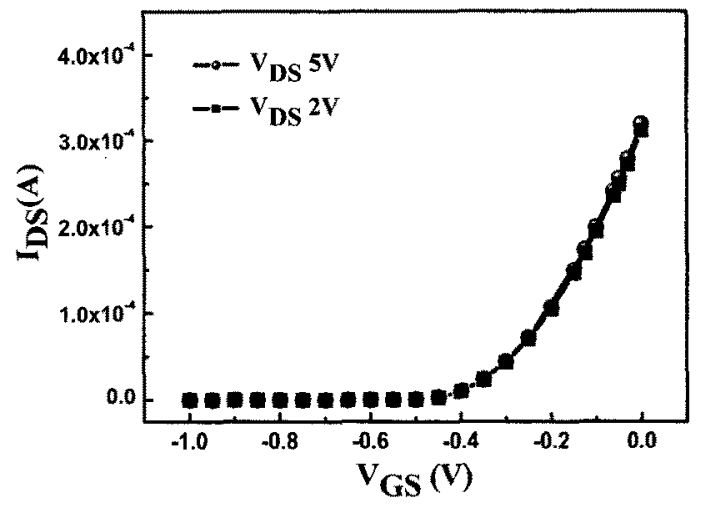

(b)

그림 3. JFET의 $\mathrm{I}-\mathrm{V}$ 특성.

Fig. 3. $1-V$ characteristic of JFET.

그래프이고, 그림 $3(\mathrm{~b})$ 는 $\mathrm{V}_{\mathrm{DS}}$ 가 각각 $2 \mathrm{~V}, 5 \mathrm{~V}$ 에서 의 $\mathrm{I}-\mathrm{V}$ 그래프이다. $\mathrm{IDSs}_{\mathrm{DS}}$ 와 $\mathrm{V}_{\mathrm{GS}(\mathrm{foff})}$ 값이 각각 300 $\mu \mathrm{A},-0.46 \mathrm{~V}$ 일 때를 기준으로 여러 parameter (N-well, Gate, Source-Drain, Substrate)에서 각각 시간, 온도, 도평농도, implant energy에 변화를 주 어 시률레이션한 결과 시간과 온도에 의한 영향이 가장 컸고, 열처리 공정에서 Gate와 substrate에서 확산된 Boron원자가 N-Channel에 영향을 주기 때 문으로 사료된다.

3.2 Electrical property of SiGe by SiGe layer thickness

그림 4(a)는 $\mathrm{SiGe}$ 층 두께에 따른 $\mathrm{SiGe} J \mathrm{JET}$ 의 IDss 변화 값을 나타낸 것이다. SiGe층 두께가 50 $\mathrm{nm}$ 일 때 IDss는 $300 \mu$ A이었으며 이를 기준으로 두께를 $10 \mathrm{~nm}$ 씩 증가시키거나 감소시키면서 IDss 를 측정하였다.

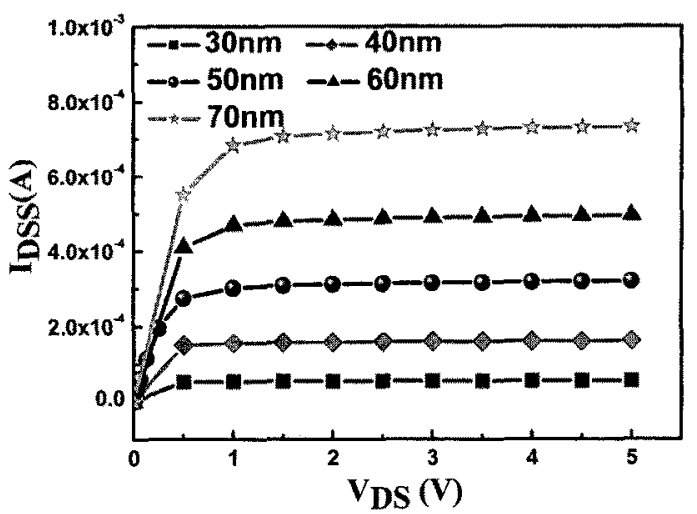

(a)

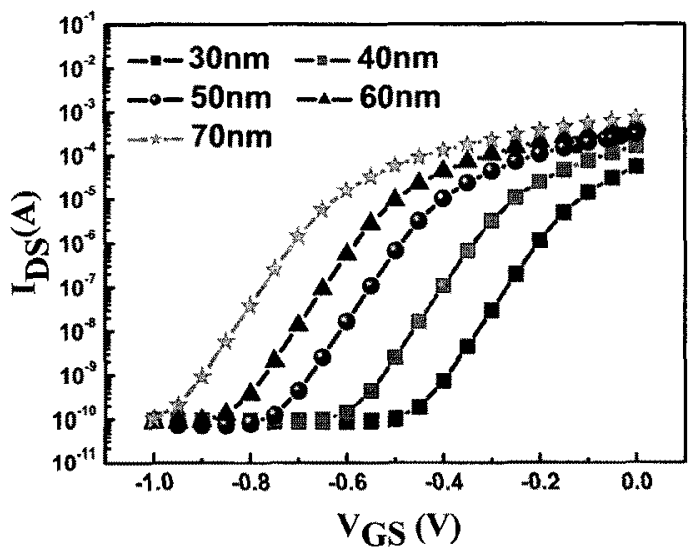

(b)

그림 4. $\mathrm{SiGe}$ 층 두께에 따른 $\mathrm{SiGe} J \mathrm{JEET}$ 의 $\mathrm{I}-\mathrm{V}$ 특성.

Fig. 4. I-V Characteristic of SiGe JFET depend on SiGe layer thickness.

그 결과 두께가 줄어들수록 $\mathrm{IDss}_{\mathrm{DS}}$ 값이 감소하는 반면에 증가할수록 IDss값이 증가하는 결과를 보이 고 있다. 그립 4(b)는 $\mathrm{SiGe}$ 층 두께에 따른 $\mathrm{SiGe}$ $\mathrm{JFET}$ 의 $\mathrm{V}_{\mathrm{GS}(\mathrm{off})}$ 변화 값을 나타낸 것이다. IDss실헙 과 마찬가지로 $\mathrm{SiGe}$ 흥 두께를 $10 \mathrm{~nm}$ 씩 증가시키 거나 감소시켰다. 그 결과 두께가 줄어들수록

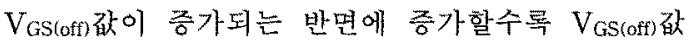
이 감소되는 것을 볼 수 있다. 이는 $\mathrm{SiGe}$ 층의 두께 가 감소할수록 Boron의 채널층으로의 확산이 증가 되어 채널 영역이 줍아지게 되고, 전류의 흐름을 방해하게 되어 IDSs값이 줄어들게 된다. 또한 채널 층이 Gate 접합부분과 가깝게 되어 $\mathrm{V}_{\mathrm{GS}(\mathrm{off})}$ 값이 증 가하는 현상이 나타난 것으로 사료된다. 


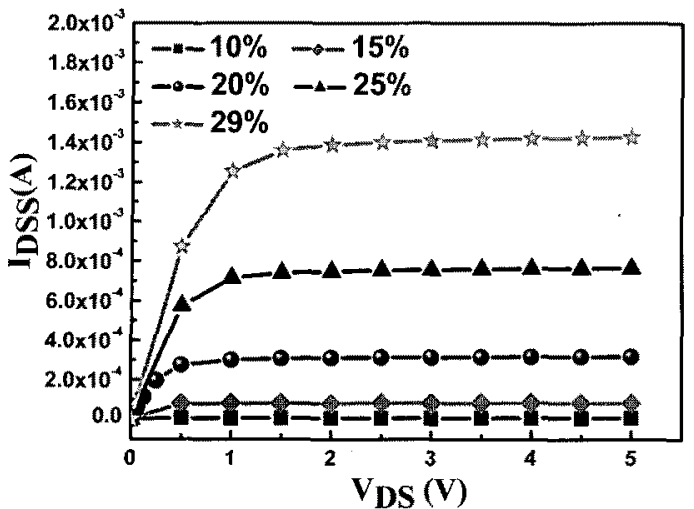

(a)

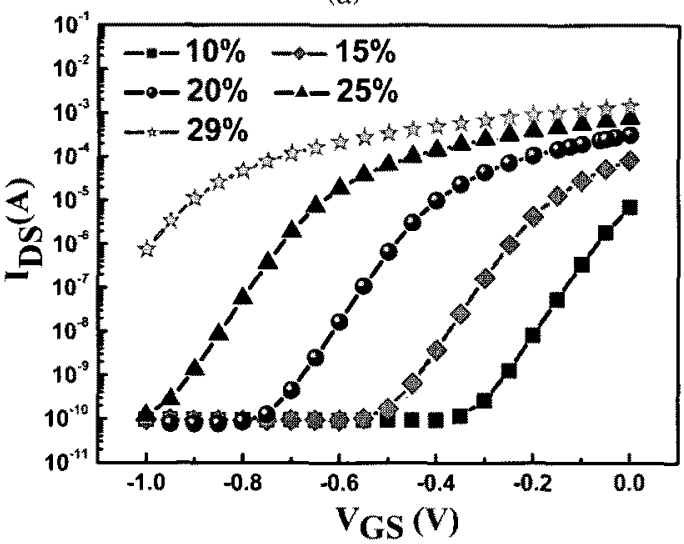

(b)

그림 5. Ge 함유량에 따른 SiGe JFET의 I-V 특성.

Fig. 5. I-V Characteristic of SiGe JFET depend on Ge mole fraction.

3.3 Electrical property of SiGe by Ge mole fraction

그림 $5(\mathrm{a})$ 는 $\mathrm{Ge}$ 함유량에 따른 $\mathrm{SiGe} J F E T$ 의 IDss변화 값을 나타낸 것이다.

$\mathrm{Ge}$ 함유량이 $20 \%$ 일 때 IDSs는 $300 \mu \mathrm{A}$ 이고 이를 기준으로 $\mathrm{Ge}$ 함유량을 $5 \%$ 씩 증가시키거나 감소시 켰다. 그 결과 함유량을 줄일수록 앞 실험예서의 두께 결과와 마찬가지로 IDss값이 감소하는 반면에 $\mathrm{Ge}$ 함유량을 늘릴수록 IDss값이 증가하였다. 그림 5(b)는 $\mathrm{Ge}$ 함유량에 따른 SiGe JFET의 $\mathrm{VGS}_{\mathrm{GS}}$ 변화 값을 나타낸 것이다. $\mathrm{Ge}$ 함유량 $20 \%$ 일 때 $\mathrm{V}_{\mathrm{GS} \text { (off) }}$ 는 $-0.46 \mathrm{~V}$ 이고 이를 기준으로 $\mathrm{Ge}$ 함유량을 $5 \%$ 증가시키거나 감소시켰다. 그 결과 $\mathrm{Ge}$ 함유량이 줄어둘수록 $V_{\text {Gstof }}$ 값이 증가되는 반면에 $\mathrm{Ge}$ 함유

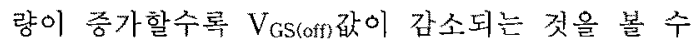
있다. 이는 $\mathrm{SiGe}$ 층에서 $\mathrm{Ge}$ 의 할유량이 감소할수록 두께 실험 결과와 마찬가지로 Boron의 확산이 증

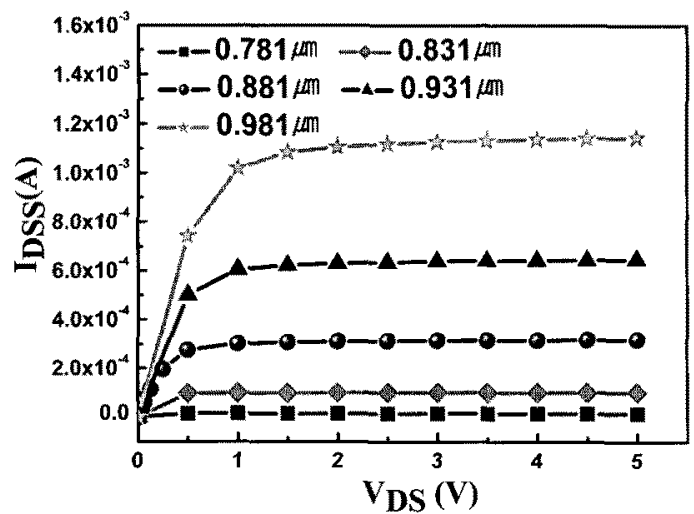

(a)

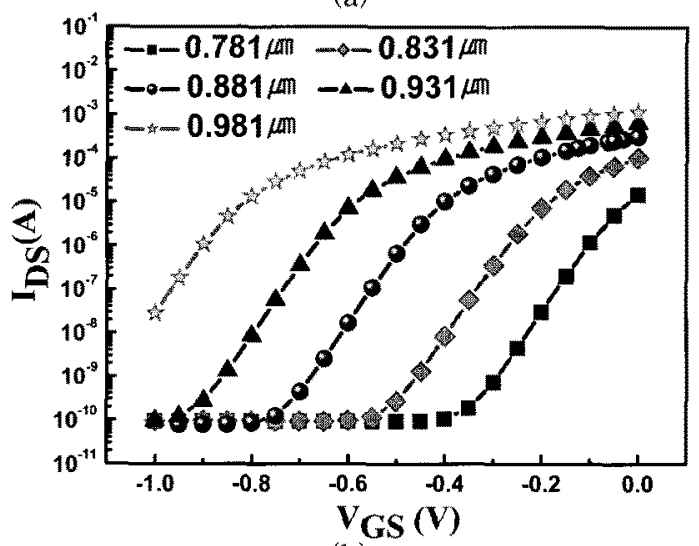

(b)

그림 6. N-Channel 두께에 따른 $\mathrm{SiGe} \mathrm{JFET}$ 의 $\mathrm{I}-\mathrm{V}$ 톡성.

Fig. 6. I-V Characteristic of SiGe JFET depend on $\mathrm{N}$-Channel thickness.

가 하게 되어 채널층을 좁게 하고 Inss값을 감소시

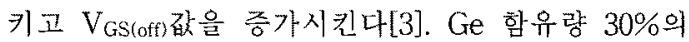
경우 과다한 전류로 인해 $\mathrm{V}_{\mathrm{GS} \text { (off) }}$ 값이 $-1 \mathrm{~V} \sim 0 \mathrm{~V}$ 범위를 넘어 버리기 때문에 $29 \%$ 로 정하였다.

3.4 Electrical property of SiGe by $\mathrm{N}$-channel thickness

그림 6(a)는 N채널 두께에 따른 $\mathrm{SiGe} J F E T$ 의 IDSs 변화 값을 나타낼 것이다.

$\mathrm{N}$ 채널 두께가 $0.881 \mu \mathrm{m}$ 일 때 $\mathrm{IDSs}$ 는 $300 \mu \mathrm{A}$ 이며 이를 기준으로 $50 \mathrm{~nm}$ 씩 증가시키거나 감소시켰다. 그 결과 두께가 감소할수록 Ioss값이 줄어드는 반 면 증가할수록 Inss값이 증가하는 결과를 보였다.

그림 6(b)는 N채널 두꼐에 따른 SiGe JFET의 $\mathrm{V}_{G S(\text { Sff) }}$ 변화 값을 나타낸 깃이다.

$\mathrm{N}$ 채널 두께가 $0.881 \mathrm{\mu m}$ 일 때를 기준으로 50 
$\mathrm{nm}$ 씩 두께 변화를 주면서 측정하였고, 두께가 감

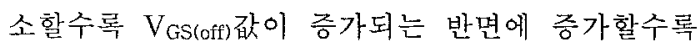

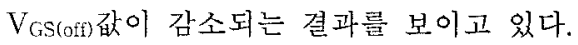

이것은 boron의 확산 현상은 SiGe layer의 두께 가 $50 \mathrm{~nm}$ 로 고정된 상태이므로 크게 영향을 끼치 지 못한 상태에서 $\mathrm{N}-$ Channel층의 두께를 줄였을 경우 $\mathrm{N}$-well 접합의 깊이가 줄어들고, $\mathrm{N}$ 채널의 폭

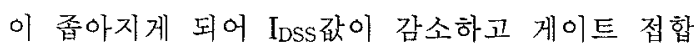
과 점점 가까워지므로 $\mathrm{V}_{\mathrm{GS}(\mathrm{off})}$ 값은 중가되는 것으 로 사료된다.

\section{4. 결 론}

본 연구에서는 기존 JFET에서 주로 나타나는 게이트 접합 부분과 기판 부분의 Boron out diffusion 현상을 막기 위한 $\mathrm{SiGe}$ 확산 저지층을 채 널 상하부에 삽입한 구조를 제안하였다. 제안된 $\mathrm{SiGe} \mathrm{JFET}$ 은 채널층에 삽입된 $\mathrm{SiGe}$ 층의 두께가 10-30 nm, Ge 함유량이 10-29\%, N채널층의 두께를 0.781-0.981 $\mu \mathrm{m}$ 으로 변화시켰을 때, $\mathrm{V}_{\mathrm{GS}(\mathrm{off})}$ 가 -0.83 $\mathrm{V}$ 까지 감소한 반면에 $\mathrm{IDss}$ 값은 최대 $1100 \mu \mathrm{A}, \mathrm{g}_{\mathrm{m}}$ 은 $1.024 \mathrm{~A} / \mathrm{V}$ 까지 증가하였다. 결국 삽입된 $\mathrm{SiGe층은}$ Boron out diffusion을 방지하여 채널이 좁아지는 현상을 막아 소자의 전기적 특성을 개선하였다.

\section{감사의 글}

본 논문은 지식경제부가 지원하는 국가 반도체 연구개발사업인 “나노반도체장비원천기술상용화사업" 을 통해 개발된 결과임을 밝힙니다.

\section{참고 문헌}

[1] J. C. Zolper, A. G. Baca, M. E. Sherwinl, and J. F. Klem "Ion Implantation for High Performance III-V JFETS and HFETS", Microwave Signal, Inc., 1996.

[2] M. Citterio, J. Kierstead, S. Rescia, P. F. Manfredi, and V. Speziali, "Low noise monolithic Si-JFET'S for operation in the $90-300 \mathrm{~K}$ range and in high radiation environments", in Proc. Symp, Low Temp. Electronics and High Temp. Superconductivity, C. L. Claeys, S. I. Raider, R. K. Kirshman, and W. D. Brown, Eds. Soc., Vol. PV 95-9, p. 418, 1995.

[3] N. R. Zangenberg, J. Fage-Pedersen, J. Lundsgaard Hansen, and A. Nylandsted Larsen, "Boron and phosphorus diffusion in strained and relaxed Si and SiGe", J. Appl. Phys., Vol. 94, No. 6, 2003. 